\title{
Association between diabetes, hypertension, activities of daily living and physical activity among elderly users of primary healthcare facilities
}

\section{Associação entre diabetes, hipertensão, atividades da vida diária e atividade física entre idosos usuários de serviços de atenção primária à saúde}

\author{
Edson Zangiacomi Martinez \\ (D) https://orcid.org/0000-0002-0949-3222 \\ Anderson Soares da Silva \\ (D) https://orcid.org/0000-0002-0824-2616 \\ Laercio Joel Franco ${ }^{1}$ \\ (D) https://orcid.org/0000-0002-9820-3425 \\ Scarlet Feitosa Santos \\ (D) https://orcid.org/0000-0002-8931-7754 \\ Natalia Akemi Yamada Terada ${ }^{1}$ \\ (D) https://orcid.org/0000-0001-6429-0594 \\ Miriane Lucindo Zucoloto \\ (D) https://orcid.org/0000-0002-4745-227X
}

Abstract - The aim of this cross-sectional study was to estimate the prevalence of self-reported hypertension and diabetes among elderly users of primary healthcare facilities in Ribeirão Preto, Brazil, and to investigate the association between these chronic conditions and physical activity and the degree of independence on the performance of activities of daily living. The study included 357 subjects aged 60 years or older. The classification of physical activity was based on the International Physical Activity Questionnaire (IPAQ) and the Pfeffer Functional Activities Questionnaire (PFAQ) was applied to assess activities of daily living. Prevalence of diabetes was associated with the level of physical activity, the self-perception of health and the degree of independence on the performance of activities of daily living. No significant associations were found between the prevalence of hypertension and these variables. These findings reinforce the relevance of continuous strategies of management of diabetes in the primary healthcare facilities based on the promotion of physical and occupational activities.

Key words: Activities of daily living; Aged; Diabetes; Hypertension; Physical activity.

Resumo - O objetivo deste estudo transversal foi estimar a prevalência auto-reportada de hipertensão e diabetes entre idosos usuários das unidades de atenção primária à saúde de Ribeirão Preto, Brasil, e investigar a associaçẫo entre estas condiçôes crônicas e a atividade física e o grau de independência na realização das atividades da vida diária. O estudo incluiu 357 participantes com idade de 60 anos ou mais. A classificação da atividade física baseou-se no International Physical Activity Questionnaire (IPAQ), e o Pfeffer Functional Activities Questionnaire (PFAQ) foi aplicado para avaliar a realização das atividades da vida diária. Prevalência de diabetes foi associada com o nivel de atividade física, a autopercepção da saúde e o grau de independência na realização das atividades da vida diária. Não foram encontradas associaçôes significantes entre a prevalência de hipertensão e estas variáveis. Estes achados reforçam a relevância de estratégias contínuas de manejo da diabetes nas unidades de atenção primária à saúde, baseadas na promoção de atividades físicas e ocupacionais.

Palavras-chave: Atividades cotidianas; Atividade física; Diabetes; Hipertensão; Idosos.
1 University of São Paulo. Ribeirão Preto Medical School. Ribeirão Preto, SP. Brazil.

Received: 07 February 2019 Accepted: 15 April 2019

How to cite this article

Martinez EZ, Silva AS, Franco LJ, Santos SF, Terada NAY, Zucoloto ML. Association between diabetes, hypertension, activities of daily living and physical activity among elderly users of primary healthcare facilities. Rev Bras Cineantropom Desempenho Hum 2019, 21:e55149. DOl: http://dx.doi.org/10.1590/19800037.2019v21e55149

Copyright: This work is licensed under a Creative Commons Attribution 4.0 International License. 


\section{INTRODUCTION}

An article published in the early 1970s reported that one of the main characteristics of Brazilian population was its extreme youth ${ }^{1}$, or rather, $42.7 \%$ of its population were composed of children under 14 years old, while only $4.9 \%$ were over 60. However, since the early 1960s the Brazilian population has been aging rapidly, when a decline in fertility rates began to change its age structure and progressively narrowed the base of the population pyramid ${ }^{2}$. Official data ${ }^{3}$ show that in 2010, people with 60 years or older accounted for $11.75 \%$ in the female population and $9.8 \%$ in the male population in Brazil. In addition, while in the 1950s the life expectancy at birth in Brazil for both sexes was less than 50 years, in 2013 it was estimated at 74.8 years ${ }^{4}$. The aging of the Brazilian population and the subsequent changes in its epidemiological profile led to the need for establishing special strategies aimed at the elderly, including public policies for health promotion in the face of the increased occurrence of chronic illnesses and functional disabilities and the need of studies in order to know the demand for health care.

Along with complications such as mood disorders, dementia and falls, the development of chronic diseases as diabetes mellitus (DM) lower the chances of successful ageing, increase functional limitation, and impair quality of life 5 . In 2013, the International Diabetes Federation (IDF) estimated a prevalence of diabetes in Brazil of $9.19 \%{ }^{6}$. In elderly population, the prevalence of DM is higher than that in the general population. A cross-sectional study conducted in Viçosa, Minas Gerais, Brazil, with elderly people aged 60 years or older, estimated a self-reported prevalence of diabetes of $22.4 \%{ }^{7}$. DM prevalence among the elderly living in the city of São Paulo, Brazil, was estimated to be $17.9 \%^{8}$. In a population-based study with a probabilistic sample of elderlies in Goiânia, Goiás, Brazil, 19.0\% self-reported DM ${ }^{9}$. Arterial hypertension (AH) is also highly prevalent in Brazil. The National Health Survey, 2013, estimated the self-reported $\mathrm{AH}$ prevalence in the Brazilian population aged 60 to 64 years to be $44.4 \%{ }^{10}$. Among the elderly aged 65 to 74 years, the AH prevalence was $52.7 \%{ }^{10}$. In Brazil, the prevalence of chronic diseases has been also associated with black or indigenous ethnicity, lower schooling levels and lack of private health insurance ${ }^{11,12}$.

Evidence from epidemiological studies suggests that diabetes is also a risk factor for functional limitations and disability in elderly subjects ${ }^{13,14}$. One hypothesis that can explain this relation is that diabetes has been associated with a faster decline in cognitive function, as well as increased incidence of falls $s^{15,16}$. In addition, chronic hyperglycemia is an indicator of diabetes and it is associated with muscle weakness, which may cause difficulties in performing daily activities ${ }^{16}$.

Therefore, the aim of the present observational cross-sectional study was to estimate the prevalence of self-reported hypertension and diabetes among elderly users of primary healthcare facilities in Ribeirão Preto, Brazil, and to identify variables that may be associated with these chronic conditions. These variables include the physical activity classified by the 
International Physical Activity Questionnaire (IPAQ) and the degree of independence on the performance of activities of daily living, measured by the Pfeffer Functional Activities Questionnaire (PFAQ). The present study differs from most previous studies in three ways. First, it was focused on a specific population of interest rather than general population, which allows us to study in detail the elderly people who attended the public health system. Second, the information was collected through face-to-face interviews carried out at health care facilities. Third, there are few articles describing the concurrent prevalence of self-reported DM and AH.

\section{METHOD}

\section{Study design and place}

This cross-sectional study included 357 subjects aged 60 years or older living in the municipality of Ribeirão Preto, Southeast region of Brazil, users of primary health care services. The overall population of Ribeirão Preto is about 670 thousand inhabitants, being among the thirty largest Brazilian municipalities. Nearly $11 \%$ of its population is composed of people aged 60 and over. Healthcare facilities in Ribeirão Preto are organized into five geographical areas (North, South, East, West and Central Health Districts) with distinct demographic characteristics. It is estimated that $52 \%$ of its urban population has exclusive use of the public healthcare resources and $80 \%$ use these facilities at some time. In each Health Districts there is a Basic and District Health Unit (UBDS or, in Portuguese, Unidade Básica e Distrital de Saúde) that is the reference point for some medical specialties in the respective region. Assuming that the elderly attending the UBDS to seek primary care services represent the population of elderly users of the units located in the coverage area of the corresponding Health District, the data collection was performed in each of the five UBDS of Ribeirão Preto. Using a formula for sample size for a proportion estimate with relative precision ${ }^{17}$, the sample size of 357 subjects is sufficient to estimate a prevalence rate close to 0.5 (corresponding to the maximum variance) with precision of approximately $10 \%$ and a confidence coefficient of $95 \%$.

\section{Data collection instruments and measures}

People with a given self-reported condition were defined as those who responded "yes" to the question: "Have you ever heard from a doctor, at some moment in your life, that you have/had X?", where X denotes the respective condition (DM or $\mathrm{AH}$ ). Socioeconomic status was assessed based on the acquisition of material goods and the schooling of the head of the household, as proposed by the Brazilian Association of Research Institutions. In an order from the most privileged socioeconomic class to the least privileged class, the possible classifications are as follows: A, B1, B2, C1, C2, D and E. The educational level was classified into four groups: no schooling (including illiterates and people who have never attended school), elementary/middle (incomplete or complete), high school 
(incomplete or complete), and higher education (incomplete or complete). Smoking was coded as never smoked, ex-smoker, or current smoker.

The classification of physical activity was based on the International Physical Activity Questionnaire (IPAQ) modified for the elderly and adapted to the Brazilian-Portuguese language by Mazo and Benedetti ${ }^{18}$. IPAQ classified the participants into three categories: low, moderate and high (or vigorous) physical activity.

The Pfeffer Functional Activities Questionnaire (PFAQ ${ }^{19,20}$ was applied to assess activities of daily living. PFAQ evaluates of the degree of independence on the performance of ten instrumental activities of daily living: (a) writing checks, paying bills, or keeping financial records; (b) assembling tax records, business affairs, or papers; (c) shopping alone for clothes, household necessities or groceries; (d) playing a game of skill or working on a hobby; (e) heating water, making a cup of coffee, or turning off the stove; (f) preparing meals; (g) keeping track of current events; (h) watching news reports and discussing them; (i) remembering appointments, family occasions, holidays, or medications; and ( $\mathrm{j}$ ) traveling out of the neighborhood, driving, or arranging to take airplane, train or buses. The performance in each of these activities is assessed with a scoring ranging from $0-3$, according to increasing severity. The maximum possible score is 30 , and subjects who score higher than five are considered to have functional impairment ${ }^{21}$.

\section{Data collection}

Data collection was conducted between January and February 2017. First, authors contacted the Ribeirão Preto Municipal Health Secretariat in order to obtain authorization for the data collection. After approval by the Ethics Committee, data were collected by face-to-face interview by three trained interviewers. Participants were invited to participate in the study while they were waiting for medical care in the health facilities. Only elderly individuals (60 years old or more) who agreed and signed informed consent forms were interviewed.

\section{Data analysis}

$\mathrm{DM}$ and $\mathrm{AH}$ prevalence was estimated with their respective $95 \%$ confidence intervals $(95 \% \mathrm{CI})$ based on the exact method ${ }^{17}$. Logistic regression models were used to assess the association between the prevalence of DM and AH and participants' characteristics, with age and sex adjustments. Considering the PFAQ scores as the dependent variable and age groups, sex and prevalence of DM (or AH) as the independent variables, beta-binomial models were evaluated using SAS PROC FMM. The use of these models is justified by the assumption that the PFAQ scores can be considered as a discrete variable. For statistical analysis, we used the SAS System statistical software version 9.4 for Windows (SAS Institute, Cary, North Carolina).

\section{Ethical statement}

The Ethics Committee from the Health School Center of the Ribeirão Preto Medical School (University of São Paulo, Brazil) reviewed and approved this research. Written informed consent was obtained from all the participants. 


\section{RESULTS}

The sample was composed of 224 (63\%) females with mean age of 71.4 years (standard deviation [SD] 7.5) and 133 (37\%) males with mean age of 69.9 years (SD 6.8). Self-reported DM prevalence among females was $24.6 \%$ (95\% CI: $19.0 \%$ - 30.7\%) and among males was $28.6 \%$ (95\% CI: $21.0 \%-$ $37.0 \%)$, and self-reported AH prevalence among females was $62.1 \%$ (95\% CI: 55.3\% - 68.4\%) and among males was 53.4\% (95\% CI: 44.5\% - 62.1\%). According to the IPAQ instrument, the prevalence of high, moderate and low level of physical activity were, respectively, 28.9\%, 54.9\% and 16.2\%.

Table 1 shows the prevalence of DM and AH according to the characteristics of the elderly participants, and the age and sex-adjusted prevalence ratios $(\mathrm{PR})$ with their respective $95 \% \mathrm{CI}$. The results indicated that there was no evidence of association between DM prevalence and characteristics such as sex, age, educational level, marital status, and socioeconomic status. However, we can observe a higher prevalence of DM among the elderly individuals who reported regular or poor perception of health, among those with low level of physical activity, and among those considered to have functional impairment (PFAQ scores higher than five). Table 1 also shows that there was no evidence of association between $\mathrm{AH}$ prevalence and the variables considered, except for a significant effect of age (it is found a higher $\mathrm{AH}$ prevalence among elderly people aged 75 or more).

Table 2 presents the results of the descriptive measures (mean, standard deviation and minimum and maximum values) of the PFAQ scores according to the self-reports of DM and age groups. P values showed in Table 2 were obtained from beta-binomial regression models and compare PFAQ mean scores between participants who reported and did not report DM, in each age group. Considering the PFAQ scores as the dependent variable, this regression model detected a significant effect of sex, age groups, $\mathrm{AH}$, and interaction terms between age groups and $\mathrm{AH}$. Thus, it is possible to note that the degree of dependence on the activities of daily living tend to increase as the age of the participants increases. In addition, the PFAQ mean scores are statistically different between participants aged 75 years or older who reported and did not report DM $(\mathrm{p}<0.01)$.

Table 3, analogously to Table 2 , shows the results of the descriptive of the PFAQ scores according to the self-reports of AH and age groups. A beta-binomial regression model detected a significant effect of sex and age groups on the PFAQ scores, but did not show a significant effect of AH.

Table 4 shows the DM prevalence according to the dependence in activities of daily living, given by each item of the PFAQ. We have observed significant associations between the DM prevalence and the items 3 (shopping alone for clothes, household necessities, and groceries), 4 (playing a game of skill, working on a hobby), and 9 (remembering out neighborhood, driving, arranging to take bus). We also studied the associations between AH prevalence and activities of daily living, but we did not find significant associations (these results were not shown, for parsimony). 
Table 1. Age-and-sex adjusted prevalence ratios (PR) for self-reported DM and AH.

\begin{tabular}{|c|c|c|c|c|c|c|c|}
\hline \multirow[b]{2}{*}{ Variables } & \multirow[b]{2}{*}{ Total } & \multicolumn{3}{|c|}{ DM prevalence } & \multicolumn{3}{|c|}{ AH prevalence } \\
\hline & & $n$ & $\%$ & $P R(95 \% \mathrm{Cl})$ & $n$ & $\%$ & $P R(95 \% \mathrm{Cl})$ \\
\hline \multicolumn{8}{|l|}{ Sex } \\
\hline Women & 224 & 55 & 24.6 & Ref. & 139 & 62.1 & Ref. \\
\hline Men & 133 & 38 & 28.6 & $1.2(0.8-1.7)$ & 71 & 53.4 & $0.8(0.6-1.0)$ \\
\hline \multicolumn{8}{|l|}{ Age groups (years) } \\
\hline $60-65$ & 93 & 23 & 24.7 & Ref. & 47 & 50.5 & Ref. \\
\hline $66-74$ & 156 & 45 & 28.9 & $1.1(0.7-1.8)$ & 91 & 58.3 & $1.2(0.9-1.5)$ \\
\hline 75 or more & 108 & 25 & 23.1 & $0.9(0.5-1.5)$ & 72 & 66.7 & $1.3(1.1-1.7)^{*}$ \\
\hline \multicolumn{8}{|c|}{ Private health insurance } \\
\hline No & 303 & 77 & 25.4 & Ref. & 178 & 58.8 & Ref. \\
\hline Yes & 54 & 16 & 29.6 & $1.2(0.8-1.7)$ & 32 & 59.3 & $1.0(0.7-1.3)$ \\
\hline \multicolumn{8}{|l|}{ Educational level } \\
\hline No schooling & 25 & 8 & 32.0 & Ref. & 18 & 72.0 & Ref. \\
\hline Elementary school & 238 & 60 & 25.2 & $0.7(0.3-1.3)$ & 146 & 61.3 & $0.9(0.7-1.2)$ \\
\hline Intermediate school & 68 & 21 & 30.9 & $0.9(0.4-1.8)$ & 36 & 52.9 & $0.8(0.5-1.1)$ \\
\hline Higher education & 26 & 4 & 15.4 & $0.4(0.1-1.3)$ & 10 & 38.5 & $0.5(0.3-1.0)$ \\
\hline \multicolumn{8}{|l|}{ Marital status } \\
\hline Single & 28 & 7 & 25.0 & Ref. & 12 & 42.9 & Ref. \\
\hline Married & 197 & 53 & 26.9 & $1.1(0.5-2.1)$ & 117 & 59.4 & $1.5(0.9-2.3)$ \\
\hline Divorced & 48 & 11 & 22.9 & $0.9(0.3-2.1)$ & 27 & 56.3 & $1.4(0.8-2.3)$ \\
\hline Widowed & 84 & 22 & 26.2 & $1.1(0.5-2.4)$ & 54 & 64.3 & $1.4(0.8-2.2)$ \\
\hline \multicolumn{8}{|l|}{ Socioeconomic status } \\
\hline $\mathrm{A}, \mathrm{B} 1$ or $\mathrm{B} 2$ & 92 & 22 & 23.9 & Ref. & 50 & 54.4 & Ref. \\
\hline $\mathrm{C} 1$ & 115 & 35 & 30.4 & $1.3(0.8-2.0)$ & 69 & 60.0 & $1.1(0.8-1.3)$ \\
\hline $\mathrm{C} 2$ & 95 & 16 & 16.8 & $0.6(0.3-1.2)$ & 63 & 66.3 & $1.2(0.9-1.5)$ \\
\hline $\mathrm{D}$ or $\mathrm{E}$ & 55 & 20 & 36.4 & $1.6(0.9-2.6)$ & 28 & 50.9 & $0.9(0.6-1.2)$ \\
\hline \multicolumn{8}{|c|}{ Self-perception of health } \\
\hline Good & 150 & 19 & 12.7 & Ref. & 70 & 46.7 & Ref. \\
\hline Regular & 153 & 51 & 33.3 & $3.0(1.8-4.8)^{\star}$ & 105 & 68.6 & $1.4(1.1-1.8)$ \\
\hline Poor & 54 & 23 & 42.6 & $3.6(2.1-6.1)^{*}$ & 35 & 64.8 & $1.3(1.0-1.8)$ \\
\hline \multicolumn{8}{|l|}{ Smoking status } \\
\hline Current smoker & 54 & 12 & 22.2 & Ref. & 26 & 48.2 & Ref. \\
\hline Exsmoker & 110 & 31 & 28.2 & $1.2(0.6-2.2)$ & 62 & 56.4 & $1.2(0.8-1.6)$ \\
\hline Nonsmoker & 193 & 50 & 25.9 & $1.8(0.6-2.1)$ & 122 & 63.2 & $1.3(0.9-1.7)$ \\
\hline \multicolumn{8}{|l|}{ IPAQ level } \\
\hline High & 103 & 20 & 19.4 & Ref. & 58 & 56.3 & Ref. \\
\hline Moderate & 196 & 50 & 25.5 & $1.3(0.8-2.1)$ & 116 & 59.2 & $1.0(0.8-1.3)$ \\
\hline Low & 58 & 23 & 39.7 & $2.1(1.2-3.5)^{\star}$ & 36 & 62.1 & $1.0(0.7-1.3)$ \\
\hline \multicolumn{8}{|l|}{ Use of any device } \\
\hline No & 332 & 86 & 25.9 & Ref. & 193 & 58.1 & Ref. \\
\hline Yes & 25 & 7 & 28.0 & $1.1(0.5-2.1)$ & 17 & 68.0 & $1.1(0.8-1.5)$ \\
\hline \multicolumn{8}{|l|}{ Limitation due to pain } \\
\hline Never & 143 & 32 & 22.4 & Ref. & 75 & 52.5 & Ref. \\
\hline Rarely & 36 & 9 & 25.0 & $1.2(0.6-2.3)$ & 24 & 66.7 & $1.2(0.8-1.6)$ \\
\hline Occasionally & 73 & 22 & 30.1 & $1.4(0.8-2.3)$ & 44 & 60.3 & $1.1(0.8-1.4)$ \\
\hline Oftentimes & 47 & 9 & 19.2 & $0.8(0.4-1.7)$ & 27 & 57.5 & $1.1(0.8-1.5)$ \\
\hline Always & 58 & 21 & 36.2 & $1.8(1.1-2.9)^{\star}$ & 40 & 69.0 & $1.2(0.9-1.6)$ \\
\hline \multicolumn{8}{|c|}{ Functional impairment (PFAQ) } \\
\hline No $($ score $\leq 5)$ & 290 & 70 & 24.1 & Ref. & 166 & 57.2 & Ref. \\
\hline Yes (score > 5) & 67 & 23 & 34.2 & $1.5(1.1-2.2)^{\star}$ & 44 & 65.7 & $1.1(0.8-1.3)$ \\
\hline
\end{tabular}

Note. Confidence intervals that do not include 1 are marked with an asterisk (similar to $p<0.05$ ); PR: prevalence ratio. Cl: confidence interval. DM: diabetes mellitus. AH: arterial hypertension. PFAQ: Pfeffer Functional Activities Questionnaire Ref.: reference class. 
Table 2. Descriptive measures of the PFAQ scores according to the self-reports of DM and age groups.

\begin{tabular}{lccccccc}
\hline & \multicolumn{3}{c}{ Participants who did not reported DM } & \multicolumn{5}{c}{ Participants who reported DM } \\
\hline Age groups (years) & $\mathrm{n}$ & Mean (SD) & Min-Max & $\mathrm{n}$ & Mean (SD) & Min-Max & $P$ value \\
\hline $60-65$ & 70 & $1.86(3.15)$ & $0-19$ & 23 & $2.70(3.60)$ & $0-13$ & 0.10 \\
$66-74$ & 111 & $2.69(3.58)$ & $0-18$ & 45 & $2.84(4.40)$ & $0-26$ & 0.99 \\
75 or more & 83 & $3.87(4.45)$ & $0-20$ & 25 & $7.48(6.94)$ & $0-25$ & $<0.01$ \\
\hline
\end{tabular}

Note. DM: diabetes mellitus. SD: standard deviation.

Table 3. Descriptive measures of the PFAQ scores according to the self-reports of $\mathrm{AH}$ and age groups.

\begin{tabular}{lccccccc}
\hline & \multicolumn{3}{l}{ Participants who did not reported AH } & \multicolumn{4}{c}{ Participants who reported AH } \\
\hline Age groups (years) & $\mathrm{n}$ & Mean (SD) & Min-Max & $\mathrm{n}$ & Mean (SD) & Min-Max & $P$ value \\
\hline $60-65$ & 46 & $2.09(3.66)$ & $0-19$ & 47 & $2.04(2.87)$ & $0-11$ & 0.76 \\
$66-74$ & 65 & $2.25(3.09)$ & $0-16$ & 91 & $3.09(4.25)$ & $0-26$ & 0.60 \\
75 or more & 36 & $4.67(5.87)$ & $0-25$ & 72 & $4.72(5.07)$ & $0-19$ & 0.95 \\
\hline
\end{tabular}

Note. AH: arterial hypertension. SD: standard deviation.

Table 4. Association between self-reported DM prevalence and the activities of daily living.

\begin{tabular}{|c|c|c|c|c|}
\hline \multirow{2}{*}{ Activities of daily living } & \multirow[b]{2}{*}{ Total } & \multicolumn{3}{|c|}{ DM prevalence } \\
\hline & & $\mathrm{n}$ & $\%$ & $P R(95 \% \mathrm{Cl})$ \\
\hline \multicolumn{5}{|c|}{ 1. Writing checks, paying bills, or keeping financial records } \\
\hline Have no dependency & 252 & 63 & 25.0 & Ref. \\
\hline Have some degree of dependency & 105 & 30 & 28.6 & $1.2(0.8-1.7)$ \\
\hline \multicolumn{5}{|c|}{ 2. Assembling tax records, business affairs, or papers } \\
\hline Have no dependency & 194 & 46 & 23.7 & Ref. \\
\hline Have some degree of dependency & 163 & 47 & 28.8 & $1.2(0.8-1.7)$ \\
\hline \multicolumn{5}{|c|}{ 3. Shopping alone for clothes, household necessities, and groceries } \\
\hline Have no dependency & 310 & 74 & 23.9 & Ref. \\
\hline Have some degree of dependency & 47 & 19 & 40.4 & $1.8(1.1-2.7)^{\star}$ \\
\hline \multicolumn{5}{|c|}{ 4. Playing a game of skill, working on a hobby } \\
\hline Have no dependency & 289 & 69 & 23.9 & Ref. \\
\hline Have some degree of dependency & 68 & 24 & 35.3 & $1.5(1.1-2.3)^{\star}$ \\
\hline \multicolumn{5}{|c|}{ 5. Heat water, make a cup of coffee, turn off stove } \\
\hline Have no dependency & 334 & 85 & 25.4 & Ref. \\
\hline Have some degree of dependency & 23 & 8 & 34.8 & $1.4(0.7-2.5)$ \\
\hline \multicolumn{5}{|l|}{ 6. Preparing a balanced meal } \\
\hline Have no dependency & 325 & 85 & 26.2 & Ref. \\
\hline Have some degree of dependency & 32 & 8 & 25.0 & $0.9(0.4-1.8)$ \\
\hline \multicolumn{5}{|l|}{ 7. Keeping track of current events } \\
\hline Have no dependency & 329 & 82 & 24.9 & Ref. \\
\hline Have some degree of dependency & 28 & 11 & 39.3 & $1.7(1.0-2.8)$ \\
\hline \multicolumn{5}{|c|}{ 8. Paying attention to, understanding, discussing TV, book, magazine } \\
\hline Have no dependency & 319 & 80 & 25.1 & Ref. \\
\hline Have some degree of dependency & 38 & 13 & 34.2 & $1.4(0.8-2.3)$ \\
\hline \multicolumn{5}{|c|}{ 9. Remembering appointments, family occasions, holidays, medications } \\
\hline Have no dependency & 253 & 58 & 22.9 & Ref. \\
\hline Have some degree of dependency & 104 & 35 & 33.7 & $1.5(1.1-2.1)^{\star}$ \\
\hline \multicolumn{5}{|c|}{ 10. Traveling out of neighborhood, driving, arranging to take buses } \\
\hline Have no dependency & 301 & 75 & 24.9 & Ref. \\
\hline Have some degree of dependency & 56 & 18 & 32.1 & $1.4(0.9-2.2)$ \\
\hline
\end{tabular}

Note. Confidence intervals that do not include 1 are marked with an asterisk (similar to $p<0.05$ ); PR: prevalence ratio. Cl: confidence interval. DM: diabetes mellitus. 


\section{DISCUSSION}

Studies of the prevalence of chronic diseases among users of primary healthcare facilities are important for several reasons. Primary healthcare services have an essential role in various aspects of prevention, detection and management of chronic conditions in the general population. Thus, these studies can contribute to a better understanding of the dynamics of chronic diseases, describing the more susceptible segments of the population in which prevention strategies should be aimed at and implemented, or in which there is more demand for treatment and patient education toward health promotion. This knowledge can improve the decision-making processes in the public health system and the general health in the community.

In the present study, self-reported DM prevalence among females was $24.6 \%$ and among males was $28.6 \%$. These values are very close to that obtained in a previous study ${ }^{22}$ among users of primary health care facilities of Ribeirão Preto (24.3\% for the overall population of individuals aged 60 years or older). A former study based on home interviews conducted in 1996 in Ribeirão Preto, showed a self-reported DM prevalence among women of $23.1 \%$ among females and $19.2 \%$ among males aged 60 years or older ${ }^{23}$. Although the prevalence of DM among females found in the present study is similar to that found by these authors ${ }^{23}$, we estimate a higher prevalence among males. A possible explanation is that it is well known that, in Brazil, men use healthcare services less than women ${ }^{24}$ and the prevalence of chronic conditions among men users of primary health care facilities can be higher to that founded in the general population, given that men tend to seek for medical care supposedly at a later stage of illness.

The present study estimated a prevalence of self-reported DM of $19.4 \%$ among participants with high level of physical activity, and of $39.7 \%$ among participants with low level of physical activity. In fact, a systematic review of published studies with meta-analysis ${ }^{25}$ provided strong evidence for an inverse association between physical activity and risk of type 2 diabetes, which may partly be mediated by reduced adiposity. Another systematic review with meta-analysis ${ }^{26}$ studied the effectiveness of physical activity intervention programs on different outcome measures in individuals with prediabetes and concluded that the intervention has a favorable effect on improving oral glucose tolerance and fasting blood sugar, and it showed a favorable effect on glycated hemoglobin, maximum oxygen uptake, and body composition. Considering that prediabetes is a strong risk factor for the development of DM, this systematic review suggests that the physical activity promotion can help to slow down the progression of disease in individuals with prediabetes. On the other hand, the present study did not find any association between physical activity and the prevalence of selfreported AH. However, a recent systematic review with meta-analysis of cohort studies ${ }^{27}$ showed a significant association between physical activity and hypertension risk across studies. This study also shows that estimate the quantitative dose-response association between physical activity and 
hypertension is not an easy task, and may require more complex study designs and more sophisticated analytical tools. Anyway, these results suggest that modification in lifestyle plays an important role to avoid the prognosis of DM and $\mathrm{AH}$ and its complications in future.

Results in Table 1 show a higher prevalence of DM among the elderly people considered to have functional impairment (PFAQ scores higher than five). In addition, Table 4 shows that the activities of daily living whose dependence is significantly associated with prevalence of DM are: (a) shopping alone for clothes, household necessities or groceries; (b) playing a game of skill or working on a hobby; and (c) remembering appointments, family occasions, holidays, or medications. These activities have in common the use of cognitive capacities to be satisfactorily performed. In fact, a systematic overview of published prospective observational studies showed that, compared to people without diabetes, people with diabetes have a greater rate of decline in cognitive function and a greater risk of cognitive decline. Other studies have been shown that elderly people with diabetes have considerable functional impairment associated with reduced health status ${ }^{28,29}$.

The main limitation of this study is its cross-sectional design, in which causal inferences cannot be made. We do not take into account important aspects of the chronic conditions, as the diagnostic time, chronicity of the disease and treatments. Other limitation is that estimates of self-reported $\mathrm{DM}$ and $\mathrm{AH}$ prevalence are always subject to underreporting. A Brazilian study showed a low sensitivity (57.1\%) for self-reported DM, suggesting that this measure may not be suitable as an indicator of disease prevalence for the Brazilian population ${ }^{30}$.

\section{CONCLUSION}

Among elderly people who attended the public health system, DM prevalence has association with the level of physical activity, the self-perception of health and the degree of independence on the performance of activities of daily living. These findings reinforce the relevance of continuous strategies of management of DM in the primary healthcare facilities based on the promotion of physical and occupational activities.

\section{COMPLIANCE WITH ETHICAL STANDARDS}

\section{Funding}

The São Paulo Research Foundation (FAPESP, grant number 16/149834), Support Foundation for Teaching, Research, and Assistance of the Clinics Hospital of the Ribeirão Preto Medical School (FAEPA, grant number 719/2019), and Unified Scholarship Program of the University of São Paulo (process number 1817).

\section{Ethical approval}

This study was approved by the Research Ethics Committee of the Ribeirão 
Preto Medical School (CAAE: 61567416.7.0000.5414). This research is in accordance with the standards set by the Declaration of Helsinki.

\section{Conflict of interest statement}

The authors have no conflict of interests to declare.

\section{Author Contributions}

Conceived and designed the experiments: EZM, MLZ, SFS, NAYT. Performed the experiments: MLZ, SFS, NAYT. Analyzed the data: EZM, ASS, LJF, MLZ. Contributed reagents/materials/analysis tools: EZM, ASS, LJF, SFS, NAYT, MLZ. Wrote the paper: EZM, ASS, LJF, SFS, NAYT, MLZ.

\section{REFERENCES}

1. Yunes J. The population of Brazil. Rev Saúde Pública 1972; 6(4): 393-404.

2. Chaimowicz F. Health of the Brazilian elderly population on the eve of the 21 st century: current problems, forecasts and alternatives. Rev Saúde Pública 1997; 31(2): 184-200.

3. Instituto Brasileiro de Geografia e Estatística/IBGE. Projeção da População do Brasil por sexo e idade: 2000-2060. 2014 [cited 2017 March 28]. Available from http://www.ibge.gov.br/home/estatistica/populacao/projecao_da_populacao/2013/ default_tab.shtm

4. Camargos MCS, Gonzaga MR. Live longer and better? Estimates of healthy life expectancy in the Brazilian population. Cad Saúde Pública 2015; 31(7): 1460-72.

5. Sinclair A, Dunning T, Rodriguez-Mañas L. Diabetes in older people: new insights and remaining challenges. Lancet Diabetes Endocrinol 2015; 3(4): 275-85.

6. IDF Diabetes Atlas, 6th ed., International Diabetes Federation: Brussels, Belgium; 2013.

7. Vitoi NC, Fogal AS, Nascimento CDM, Franceschini SDCC, Ribeiro AQ. Prevalence and associated factors of diabetes in the elderly population in Viçosa, Minas Gerais, Brazil. Rev Bras Epidemiol 2015; 18(4): 953-65.

8. Mendes TDAB, Goldbaum M, Segri NJ, Barros MBDA, Cesar CLG, Carandina L, Alves MCGP. Diabetes mellitus: factors associated with prevalence in the elderly, control measures and practices, and health services utilization in São Paulo, Brazil. Cad Saúde Pública 2011; 27(6): 1233-43.

9. Mello APA, Belo LADO, Pontes AEB, Pagotto V, Nakatani AYK, Martins KA. Population-based study of overweight and diabetes mellitus in elderly in the metropolitan area of Goiânia, Goiás. Geriatr Gerontol Aging 2016; 10(3): 151-7.

10. Andrade SSDA, Stopa SR, Brito AS, Chueri PS, Szwarcwald CL, Malta DC. Self-reported hypertension prevalence in the Brazilian population: analysis of the National Health Survey, 2013. Epidemiol Serv Saude 2015; 24(2):297-304.

11. Malta DC, Bernal RTI, de Souza MDFM, Szwarcwald CL, Lima MG, de Azevedo Barros MB. Social inequalities in the prevalence of self-reported chronic non-communicable diseases in Brazil: national health survey 2013. Int J Equity Health 2016; 15(1):153.

12. Barros MB, Francisco PM, Zanchetta LM, César CL. Trends in social and demographic inequalities in the prevalence of chronic diseases in Brazil. PNAD: 2003-2008. Cien Saude Colet 2011;16(9):3755-68.

13. Bossoni S, Mazziotti G, Gazzaruso C, Martinelli D, Orini S, Solerte SB, Romanelli G, Giustina A. Relationship between instrumental activities of daily living and blood glucose control in elderly subjects with type 2 diabetes. Age Ageing 2008;37(2):222-5. 
14. Wong E, Stevenson C, Backholer K, Woodward M, Shaw JE, Peeters A. Predicting the risk of physical disability in old age using modifiable mid-life risk factors. J Epidemiol Community Health 2015; 69(1):70-6.

15. Lu F-P, Lin K-P, Kuo H-K. Diabetes and the risk of multi-system aging phenotypes: a systematic review and meta-analysis. Plos One 2009;4:e4144.

16. Koye DN, Shaw JE, Magliano DJ Diabetes and disability in older Australians: The Australian Diabetes, Obesity and Lifestyle (AusDiab) study. Diabetes Res Clin Pract 2017;126:60-67.

17. Fleiss JL, Levin B, Paik MC. Statistical methods for rates and proportions. New York: John Wiley \& Sons; 2013.

18. Mazo GZ, Benedetti TRB. Adaptation of the International Physical Activity Questionarie for the elderly. Rev Bras Cineantropom Desempenho Hum 2010; 12(6):480-4.

19. Pfeffer RI, Kurosaki TT, Harrah CH Jr, Chance JM, Filos S. Measurement of functional activities in older adults in the community. J Gerontol 1982;37(3):323-9.

20. Fuentes-García, A. (2014). Pfeffer Functional Activities Questionnaire. In Encyclopedia of Quality of Life and Well-Being Research (pp. 4789-4792). Springer Netherlands.

21. Laks J, Batista EM, Guilherme ER, Contino AL, Faria ME, Rodrigues CS, de Paula E, Engelhardt E. Prevalence of cognitive and functional impairment in community-dwelling elderly: importance of evaluating activities of daily living. Arq Neuropsiquiatr 2005;63(2A):207-12.

22. Martinez EZ, Terada NAY, Giglio FM, Zucoloto ML. Prevalence of self-reported diabetes and hypertension among users of primary health care services. Acta Sci Health Sciences 2018; 40: e34781.

23. Torquato MTCG, Montenegro Junior RM, Viana LAL, Souza RAHG, Lanna CMM, Lucas JCB, Bidurin C, Foss MC Prevalence of diabetes mellitus and impaired glucose tolerance in the urban population aged 30-69 years in Ribeirão Preto (São Paulo), Brazil. Sao Paulo Med J 2003;121(6):224-30.

24. Gomes R1, Nascimento EF, Araújo FC. Why do men use health services less than women? Explanations by men with low versus higher education. Cad Saude Publica 2007;23(3):565-74.

25. Aune D, Norat T, Leitzmann M, Tonstad S, Vatten LJ. Physical activity and the risk of type 2 diabetes: a systematic review and dose-response meta-analysis. Eur J Epidemiol 2015;30(7):529-42.

26. Jadhav RA, Hazari A, Monterio A, Kumar S, Maiya AG. Effect of Physical Activity Intervention in Prediabetes: A Systematic Review with Meta-analysis. J Phys Act Health 2017;14(9):745-55.

27. Cukierman T, Gerstein HC, Williamson JD. Cognitive decline and dementia in diabetes-systematic overview of prospective observational studies. Diabetologia 2005;48(12):2460-9.

28. Sinclair AJ, Conroy SP, Bayer AJ. Impact of diabetes on physical function in older people. Diabetes Care 2008;31(2):233-5.

29. Manas LR, Sinclair AJ. Diabetes and functional limitation: The emergence of frailty and disability. In: Sinclair AJ, Dunning T, Mañas LR, Munshi M, editors. Diabetes in Old Age. Fourth Edition. Chichester: John Wiley \& Sons; 2017. p. 213-24.

30. Lima-Costa MF, Peixoto SV, Firmo JO. Validity of self-reported hypertension and its determinants (the Bambuí study). Rev Saude Publica 2004;38(5):637-42.

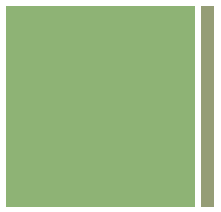

Corresponding author

Edson Zangiacomi Martinez

Av. Bandeirantes, 3900, Monte Alegre, 14049-900,

Ribeirão Preto Medical School, University of São Paulo,

Ribeirão Preto, SP, Brazil.

Email:edson@fmrp.usp.br 